\title{
Predicting Adherence and Persistence with Oral Bisphosphonate Therapy in an Integrated Health Care Delivery System
}

\author{
Rita L. Hui, PharmD, MS; Annette L. Adams, PhD, MPH; Fang Niu, MS; Bruce Ettinger, MD; \\ David K. Yi, MPH; Malini Chandra, MS, MBA; and Joan C. Lo, MD
}

\begin{abstract}
BACKGROUND: Examining drug exposure is essential to pharmacovigilance, especially for bisphosphonate (BP) therapy.

OBJECTIVE: To examine differences in 4 measures of oral BP exposure: treatment discontinuation, adherence, persistence, and nonpersistence.

METHODS: Among women aged $\geq 50$ years who initiated oral BP therapy during 2002-2007 with at least 3 years of health plan membership followup, discontinuation was defined by evidence of no further treatment during the study observation period. Among those with at least 2 filled BP prescriptions during the study period, adherence was calculated for each year of follow-up using the (modified) proportion of days covered (mPDC) metric that allows for stockpiling of prescription/refills overlap $\leq 30$ days supply. Persistence was quantified by treatment duration, allowing a gap of up to 60 days between prescription/refill days covered. Nonpersistence was quantified by the periods without drugs outside this allowable gap. Multivariable logistic regression was used to compare age and race groups and the relationships of early adherence (adherence during the first year) with subsequent adherence.
\end{abstract}

RESULTS: Among 48,390 women initiating oral BP therapy and followed for 3 years, $26.7 \%$ discontinued in year 1 , and $14.7 \%$ of the remaining 35,456 women discontinued in year 2 . Discontinuation rates were slightly higher $(29.4 \%, P<0.001)$ for women aged $\geq 75$ years and somewhat lower $(21.1 \%$, $P<0.001)$ for Asian women. During the first year, $60.4 \%$ of the women achieved an $\mathrm{mPDC}$ of $\geq 75 \%$, with demographic differences in adherence similar to that seen for treatment discontinuation. Over the 3 years, the median mPDC levels for BP therapy were $86 \%, 84 \%$, and $85 \%$ in years 1 , 2 , and 3 , respectively, for those receiving treatment. Cumulative persistence was 2.3 years (median, IQR =1.0-3.0) overall and slightly greater for Asian versus white women and lower for older women. There were 18,174 (42.9\%) women with at least 1 period of nonpersistence during 3 years follow-up in excess of the 60 -day allowable gap between prescription/refills (median cumulative nonpersistence $=0.65, \mathrm{IQR}=0.30-1.25$ years). Women with $\mathrm{mPDC} \geq 75 \%$ during the first year had a 12-fold and 6 -fold increased odds of $\mathrm{mPDC} \geq 75 \%$ during year 2 and year 3 , respectively.

CONCLUSIONS: BP discontinuation rates are highest for women during the first year. Among those continuing treatment in subsequent years, adherence rates were relatively stable. Persistence and adherence varied slightly by age and was somewhat higher in Asians, contributing to differences in cumulative BP exposure. We also found evidence that optimal adherence in the first year was highly predictive of optimal adherence in the subsequent 1-2 years. Hence, subgroups of patients receiving oral BP drugs may require different levels of support and monitoring to maximize treatment benefit, especially based on early patterns of use.

J Manag Care Spec Pharm. 2017;23(4):503-12

Copyright $\odot 2017$, Academy of Managed Care Pharmacy. All rights reserved.

\section{What is already known about this subject}

Adherence and persistence are important metrics to consider with regard to medication use, including cumulative exposure. For women initiating oral bisphosphonate (BP) therapy for osteoporosis, a large number demonstrate suboptimal adherence to therapy and discontinue treatment within the first year.

The relationship of initial and subsequent adherence measures have not been well characterized in women receiving oral BP therapy.

\section{What this study adds}

While oral BP treatment discontinuation rates declined after the first year, nonpersistence rates were high, with $43 \%$ of women having at least 1 period of nonpersistence greater than 2 months during the first 3 years.

Asian women had slightly greater adherence and persistence when compared with white women.

Among women who continued treatment, optimal adherence during the first year was strongly predictive of optimal adherence during the subsequent 2 years.

A dherence and persistence with bisphosphonate (BP) drugs are important considerations in determining long-term drug exposure, particularly in relation to fracture risk reduction and other outcomes that appear to be time and exposure dependent. Medication possession ratio (MPR) and proportion of days covered (PDC) are 2 commonly used metrics to describe adherence, ${ }^{1-3}$ whereas persistence typically refers to the length of time on therapy from initiation to discontinuation..$^{3,4}$ Numerous studies have examined adherence and persistence with BP therapy, ${ }^{2,5,6}$ where rates of discontinuation differ depending on the maximum refill gap length used to define treatment continuation. ${ }^{7}$ Other studies have proposed the term "nonpersistence" to characterize those who cease treatment and those whose treatment patterns are inconsistent, with large gaps between prescription/refills., A large body of evidence has established a strong association between BP treatment adherence and fracture risk reduction, 5,9 emphasizing the importance of optimizing the long-term benefit of continued treatment. In addition, given the unique pharmacologic properties of BP drugs (with a half-life in bone of up to 10 years $^{10}$ ), characterizing an individual's cumulative 
exposure, irrespective of treatment gaps, is also relevant for long-term safety outcomes.

Current knowledge pertaining to race-related patterns in BP adherence, persistence, and treatment continuation remains limited, particularly for Asian Americans who appear to contribute an increasing proportion of women initiating BP therapy. ${ }^{11}$ In California, Asians represent 13\%-15\% of the population, ${ }^{12}$ but they tend to be overrepresented among postmenopausal women receiving osteoporosis treatment. ${ }^{13}$ Preliminary data also suggest that Asian women appear to be at higher risk for rare adverse BP-related outcomes, ${ }^{13,14}$ emphasizing the importance of examining pharmacologic exposure patterns within this racial group. There are also limited data pertaining to BP usage over time, including the relationship of early adherence (adherence during the first year) with adherence in later years and long-term continuation. These medication behaviors may be relevant for managed care organizations developing population management tools for optimal BP use.

The purpose of this study was to examine various measures of drug use during the first 3 years after treatment initiation, the effects of age and race on these measures (particularly Asian and white race, which account for more than $80 \%$ of treated patients ${ }^{13}$ ), and the extent to which early medication usage is reflective of usage in subsequent years.

\section{Methods}

\section{Study Population}

This retrospective study was conducted within Kaiser Permanente Northern California (KPNC), a large, integrated health care delivery system with over 3 million members. Members receive hospital, ambulatory, pharmacy, and ancillary care within the same system, with data captured electronically since 1995. As previously described, ${ }^{13}$ health plan pharmacy databases were used to identify women aged 50 years and older who newly initiated oral BP therapy with either alendronate sodium, risedronate sodium, or ibandronate sodium from January 1, 2002, to December 31, 2007, and were followed for 3 years from the oral BP initiation date, excluding those without health plan membership in the previous year; those without at least 3 years of health plan membership after BP initiation (allowing membership gaps up to 2 months); those with previous receipt of oral BP therapy; and those with previous or subsequent receipt of intravenous BP therapy. The attrition graph is presented in the Appendix (available in online article). Self-reported race/ethnicity was characterized as non-Hispanic white, Asian (including Pacific Islander), and all other or unknown race/ethnicities, as previously reported. ${ }^{14}$ This study was approved by the KPNC Institutional Review Board, and a waiver of informed consent was obtained because of the nature of this study.

\section{Assessment of Bisphosphonate Exposure}

We characterized the following measures relating to BP exposure: discontinuation, adherence, and persistence (and nonpersistence). Discontinuation (defined as no further BP taken during the remaining 3-year observation period) was reported during the first year (including discontinuation after a single prescription) and during the second year after initiation of therapy. Separately, we examined the time to BP cessation for more than 6 months using Kaplan-Meier curves, censoring women after 6 months of no BP prescription/refill regardless of subsequent reinitiation of therapy. Next, we calculated adherence and persistence with BP among the subset of women who filled 2 or more BP prescriptions.

For treatment adherence, we examined the following 4 approaches described in Figure 1: (1) MPR defined as the total days supply of the drug dispensed divided by the total number of days each year (MPR was capped at a value of 1.0) $)^{1,2,4,15}$; (2) PDC using days supply of the drug dispensed to estimate the number of days that women possessed the drug for each observation year (forward stockpiling of the drug was allowed, but in contrast to MPR, prior gaps between prescriptions were not backfilled) $)^{4,15,16}$; (3) PDC where no stockpiling of drug was allowed; and (4) modified PDC (mPDC) to allow stockpiling of prescriptions that overlapped $\leq 30$ days but prioritized the second prescription if the overlap period exceeded 30 days.

We developed the mPDC approach as our primary method for characterizing ongoing drug exposure, given that PDC with stockpiling may overestimate drug exposure when there is substantial overlap of prescription/refills and PDC without stockpiling may underestimate drug exposure (only a small proportion of women had prescription/refills that overlapped more than 30 days; $9.1 \%$ in year 1, an additional $5.9 \%$ in year 2 , and $4.2 \%$ in year 3 , where the median stockpiled days of drug per person was only 53 days, interquartile range $[\mathrm{IQR}]=36-81$, over the 3 years). Adherence was characterized for each year and categorized as $\geq 50 \%, \geq 60 \%, \geq 70 \%$, and $\geq 80 \%$. An adherence optimum of $75 \%$ was also examined based on evidence of a clinically significant threshold in relation to fracture outcomes. ${ }^{9}$

The days supply coverage from the mPDC was used to examine treatment persistence, defined by the time period consistent with use of the drug, ${ }^{4}$ including an allowable gap of 60 days between the end of 1 prescription/refill to the start of the next; a gap over 60 days was used to define nonpersistence based on our previous experience examining treatment persistence with weekly alendronate therapy. ${ }^{7}$ Since BP therapy could be restarted after a period of nonpersistence, the total exposure (treatment duration) during the first 3 years of follow-up was expressed as the sum of all individual exposure periods, including the allowable gap (Figure 1). For those not $100 \%$ persistent during follow-up, the cumulative period of nonpersistence, defined by summing the gaps between exposure periods (excluding allowable gaps), was also calculated. 


\section{FIGURE 1 Calculations of Adherence and Persistence that Account for Prescription Overlaps and Gaps}

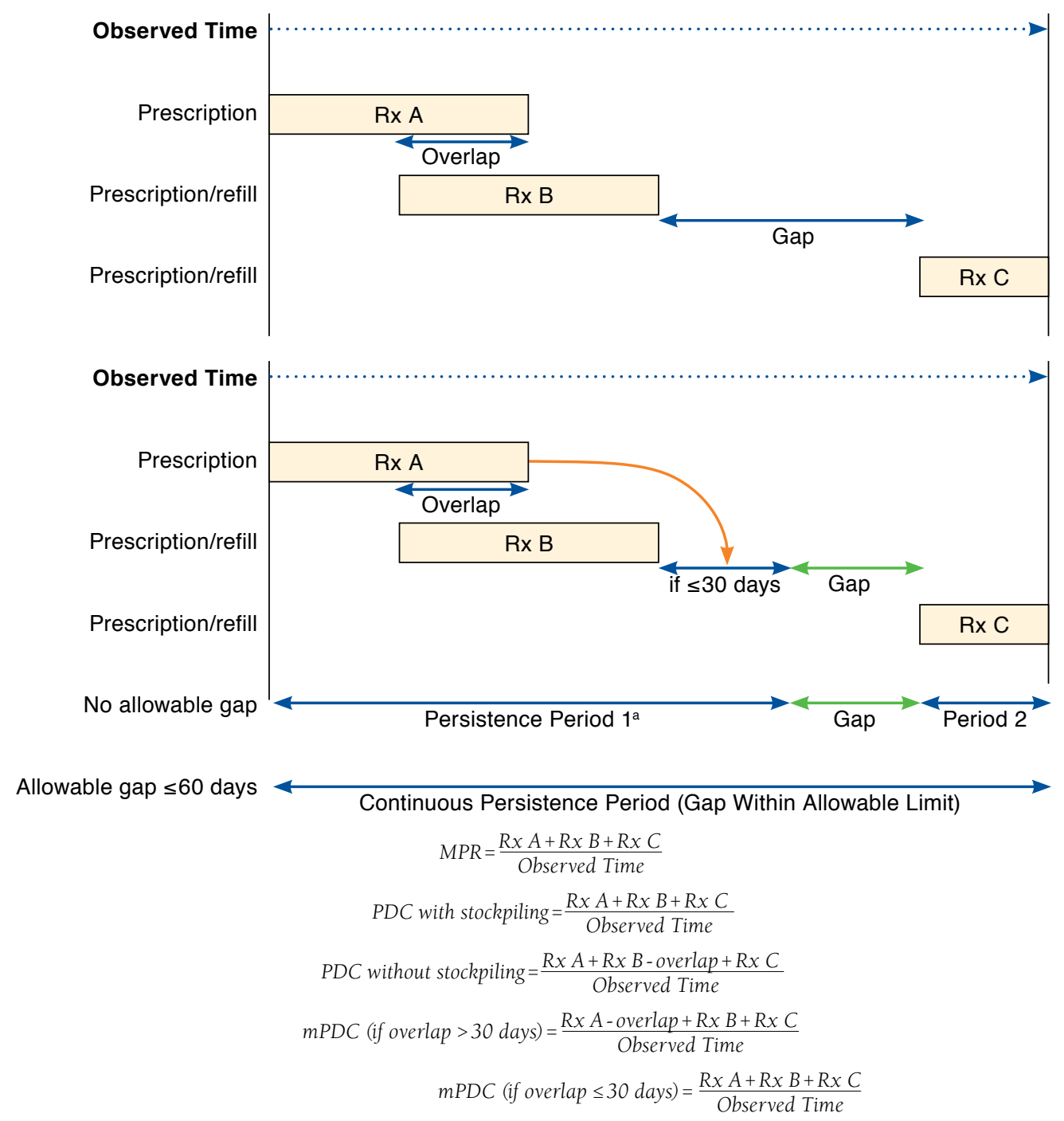

aThe persistence period reflects a treatment exposure period, where the sum of persistence periods reflects estimated treatment duration including allowable gaps. $m P D C=($ modified $)$ proportion of days covered; $M P R=$ medication possession ratio; $P D C=$ proportion of days covered; $R x=$ prescription.

Differences between age and race/ethnicity subgroups were examined using the Student's t-test or Wilcoxon rank-sum test for continuous variables and the chi-square test for categorical variables. Kaplan-Meier (K-M) estimates were used to measure the time to BP treatment cessation for more than 6 months during the 3-year observation period, with log-rank tests used to compare differences by age and race groups. The relationships between year 1 adherence (mPDC $\geq 75 \%$ ) and odds of achieving adherence (mPDC $\geq 75 \%$ ) during year 2 and year 3 were examined, adjusting for age and race groups. Two logistic regression models were fitted using the BP users in year $2(n=35,456)$ and the BP users in year $3(n=30,233)$ separately. Since mPDC value ranged from 0 to 1.00 (0\%-100\%), no outliers were identified. A $P$ value less than 0.05 was used as the criterion for statistical significance. All data were analyzed using SAS version 9.4 (SAS Institute, Cary, NC).

\section{Results}

Consistent with our previous report, there were 48,390 women who newly initiated oral BP therapy and had health plan membership at least 1 year before and up to 3 years after treatment initiation. ${ }^{13}$ More than three fourths of the women (87\%) were 


\begin{tabular}{|c|c|c|c|c|c|c|c|}
\hline & \multicolumn{4}{|c|}{ Age Groupa } & \multicolumn{3}{|c|}{ Race/Ethnicity Group ${ }^{a}$} \\
\hline & Overall & Age 50-64 & Age $65-74$ & Age $\geq 75$ & White & Asian & Other \\
\hline All patients who initiated oral BP & $\mathrm{N}=48,390$ & $\mathrm{n}=17,079$ & $\mathrm{n}=15,744$ & $\mathrm{n}=15,567$ & $\mathrm{n}=31,601$ & $\mathrm{n}=8,272$ & $\mathrm{n}=8,517$ \\
\hline $\begin{array}{l}\text { Discontinuation during year } 1 \\
\text { of follow-up, } \mathrm{n}(\%)\end{array}$ & $12,934(26.7)^{\mathrm{b}}$ & $4,310(25.2)$ & $4,044(25.7)$ & $4,580(29.4)^{c, d}$ & $8,683(27.5)$ & $1,744(21.1)^{e}$ & $2,507(29.4)^{e, f}$ \\
\hline $\begin{array}{l}\text { Patients who received oral BP } \\
\text { beyond year } 1 \text { of follow-up }\end{array}$ & $\mathrm{N}=35,456$ & $\mathrm{n}=12,769$ & $\mathrm{n}=11,700$ & $\mathrm{n}=10,987$ & $\mathrm{n}=22,913$ & $\mathrm{n}=6,528$ & $\mathrm{n}=6,010$ \\
\hline $\begin{array}{l}\text { Discontinuation during year } 2, \\
\mathrm{n}(\% \text { of users beyond year } 1)\end{array}$ & $5,223(14.7)$ & $1,883(14.7)$ & $1,690(14.4)$ & $1,650(15.0)$ & $3,491(15.2)$ & $773(11.8)^{\mathrm{e}}$ & $959(16.0)^{\mathrm{f}}$ \\
\hline $\begin{array}{l}{ }^{a} \text { Chi square tests were used for compari } \\
{ }^{b} \text { Includes } 6,027 \text { (12.5\%) women who dis } \\
{ }^{c} P<0.001 \text { compared with } 50-64 \text { years. } \\
{ }^{d} P<0.001 \text { compared with } 65-74 \text { years. } \\
{ }^{e} P<0.001 \text { compared with whites. } \\
{ }^{e} P<0.001 \text { compared with Asians. } \\
B P=\text { bisphosphonate. }\end{array}$ & $\begin{array}{l}\text { sof discontinu } \\
\text { tinued after }\end{array}$ & $\begin{array}{l}\text { rates. } \\
\text { filled BP pr }\end{array}$ & ion. & & & & \\
\hline
\end{tabular}

health plan members for at least 5 years before BP initiation. The average age of the study cohort was 69.5 (standard deviation \pm 10.0 ) years, and the cohort was ethnically diverse (65.3\% non-Hispanic white, $17.1 \%$ Asian, and $17.6 \%$ all others) as previously described. ${ }^{13}$ Approximately $86 \%$ of all oral BP prescriptions ascertained during the study period were for a 3-month supply, and 95\% of all prescriptions were prescribed as a weekly regimen. Table 1 examines the treatment discontinuation rates during the first and second year of follow-up. During the first year, 12,934 (26.7\%) women discontinued BP treatment; this included 6,027 (12.5\%) women who discontinued after only 1 filled BP prescription. For the 35,456 women receiving $\mathrm{BP}$ treatment beyond the first year, the proportion discontinuing during the second year was lower at $14.7 \%$. Across both years, the discontinuation rate was lower for Asian women compared with white women $(21.1 \%$ vs. $27.5 \%$ in year $1, P<0.001$, and $11.8 \%$ vs. $15.2 \%$ in year $2, P<0.001$ ), while age-related differences were modest and evident mainly during the first year.

In Figure 2, K-M curves show estimated time to BP treatment cessation (for more than 6 months), by age and race. By race group, Asian women had the highest continuation rates, followed by white women and those of other race/ethnicity. Women aged $\geq 75$ years also had slightly lower BP continuation rates compared with those in the other 2 age groups. The log-rank tests of the equality of the survival function were significant $(P<0.001)$ across all age and race strata, supporting the results from the K-M curves.

Among the 42,363 women with at least 2 filled BP prescriptions during the study period, we examined adherence during the first year using several methodologies. Median adherence estimates using MPR (median $=0.89, \mathrm{IQR}=0.49-1.00$ ); $\mathrm{PDC}$ with nonrestricted stockpiling (median $=0.88, \mathrm{IQR}=0.48-0.98$ ); and $\mathrm{mPDC}$ (median $=0.86, \mathrm{IQR}=0.47-0.98$ ) ranged from $86 \%$ to $89 \%$, while estimates were somewhat lower using the PDC without stockpiling of medication allowed (median $=0.81$, $\mathrm{IQR}=0.46-0.91$ ), as would be expected (Table 2). When adherence was characterized using specific thresholds ranging from $\geq 50 \%$ to $\geq 80 \%$ during the first year, a similar reduction in the proportion of adherent women was seen across each adherence measure (Figure 3). In the first year, $60.4 \%$ of the women achieved an adherence of $\geq 75 \%$ (mPDC).

Regardless of the adherence measure examined, women aged $\geq 75$ years had slightly lower BP adherence during the first year of follow-up (but not in subsequent years), while Asian women were slightly more adherent, and those of other nonwhite race/ethnicity were less adherent compared with women of white race (Table 2). Adjusting for differences in age, Asian women remained slightly more likely to achieve an adherence level of $75 \%$ (age-adjusted odds ratio $[\mathrm{OR}]=1.08$, $95 \%$ confidence interval $[\mathrm{CI}]=1.02-1.14)$, and women of other race/ethnicity were less likely (age-adjusted $\mathrm{OR}=0.74,95 \%$ $\mathrm{CI}=0.71-0.78)$ compared with white women.

For those receiving BP treatment beyond the first year of follow-up, the median mPDC levels were 0.84 (IQR $=0.46$ 0.97 ) for year 2 and $0.85(\mathrm{IQR}=0.52-0.97)$ for year 3 . Among the 30,233 women who received BP during the third year of follow-up, the median mPDCs were 0.92 (IQR=0.70-0.99), $0.89(\mathrm{IQR}=0.63-0.98)$, and $0.85(\mathrm{IQR}=0.52-0.97)$ for years 1,2 , and 3, respectively. Furthermore, 14,633 (48.4\%) of the 30,233 women had an mPDC adherence threshold of $\geq 75 \%$ during all 3 years (this represented $34.5 \%$ of all women who had at least 2 filled prescriptions).

The initial period of treatment persistence (continuous exposure) was 1.31 years (median, IQR $=0.36-3.00$ ) when a 60 -day gap was allowed before defining nonpersistence. Treatment persistence was slightly lower among older women and slightly higher among Asian women compared with white women, with 

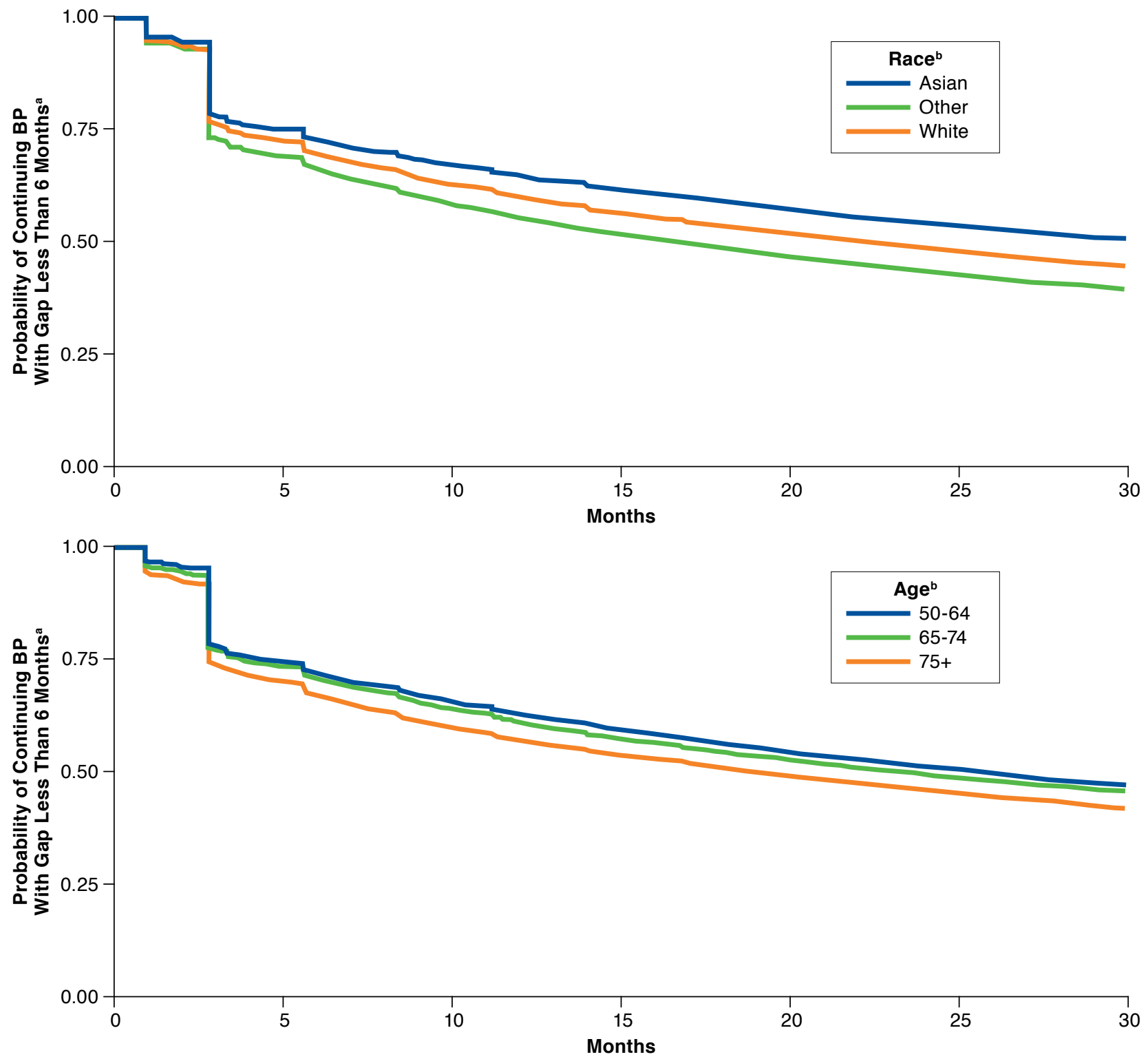

aDiscontinuation for more than 6 months was assessed between 0-30 months, with follow-up to 36 months.

${ }^{b} P<0.001$ for differences by age and race groups.

$B P=$ bisphosphonate

similar trends in cumulative BP treatment duration calculated from successive periods of treatment persistence (Table 2). During follow-up, the overall median cumulative BP treatment duration was 2.29 years (IQR=0.96-3.00), representing an exposure period that was slightly longer when compared with the total days supply (median $=2.07$ years, $I Q R=0.92-2.76$ ), which excluded all gaps between prescription or refill coverage, with a median difference of only 34 days (IQR =4-78). At least some degree of nonpersistence, defined as the time intervals between successive treatment persistence periods, was evident in 18,174 (42.9\%) women, where the median cumulative time off treatment was 0.65 years (IQR=0.30-1.25) and the median number of off-treatment intervals during the 3 years of observation was $1(\mathrm{IQR}=1-2)$. 
TABLE 2 Adherence, Persistence, and Nonpersistence with Oral BP Therapy by Age and Race/Ethnicity Subgroup

\begin{tabular}{|c|c|c|c|c|c|c|c|c|}
\hline & & \multirow[b]{2}{*}{$\begin{array}{c}\text { Overall } \\
\mathrm{N}=42,363\end{array}$} & \multicolumn{3}{|c|}{ Age Group ${ }^{a}$} & \multicolumn{3}{|c|}{ Race/Ethnicity Group ${ }^{a}$} \\
\hline & & & $\begin{array}{l}\text { Age } 50-64 \\
\mathrm{n}=14,969\end{array}$ & $\begin{array}{c}\text { Age } 65-74 \\
\mathbf{n}=3,934\end{array}$ & $\begin{array}{l}\text { Age } \geq 75 \\
\mathbf{n}=13,460\end{array}$ & $\begin{array}{c}\text { White } \\
\mathbf{n}=27,584\end{array}$ & $\begin{array}{c}\text { Asian } \\
\mathbf{n}=7,443\end{array}$ & $\begin{array}{c}\text { Other } \\
\mathbf{n}=7,336\end{array}$ \\
\hline \multicolumn{9}{|c|}{ Persistence $^{b}$} \\
\hline \multicolumn{2}{|c|}{$\begin{array}{l}\text { Initial period of persistence in } \\
\text { years, median (IQR) }\end{array}$} & $1.31(0.36-3.00)$ & $1.39(0.45-3.00)$ & $1.33(0.36-3.00)^{\mathrm{c}}$ & $1.19(0.31-3.00)^{\mathrm{d}, \mathrm{e}}$ & $1.37(0.37-3.00)$ & $1.54(0.40-3.00)^{\mathrm{f}}$ & $0.98(0.27-3.00)^{\mathrm{f}, \mathrm{g}}$ \\
\hline \multicolumn{2}{|c|}{$\begin{array}{l}\text { S cumulative periods of persis- } \\
\text { tence in years, median (IQR) }\end{array}$} & $2.29(0.96-3.00)$ & $2.35(1.06-3.00)$ & $2.33(0.97-3.00)$ & $2.17(0.84-3.00)^{\mathrm{d}, \mathrm{e}}$ & $2.30(0.95-3.00)$ & $2.54(1.22-3.00)^{f}$ & $1.98(0.83-3.00)^{\mathrm{f}, \mathrm{g}}$ \\
\hline \multicolumn{2}{|c|}{$\begin{array}{l}\text { Days supply of drug (in years) } \\
\text { over } 3 \text { years, median (IQR) }\end{array}$} & $2.07(0.92-2.76)$ & $2.07(0.92-2.76)$ & $2.07(0.92-2.76)$ & $1.96(0.77-2.75)^{\mathrm{d}, \mathrm{e}}$ & $2.07(0.92-2.76)$ & $2.29(1.15-2.81)^{\mathrm{f}}$ & $1.79(0.77-2.65)^{\mathrm{f}, \mathrm{g}}$ \\
\hline \multicolumn{9}{|l|}{ Adherence } \\
\hline \multirow{4}{*}{$\begin{array}{l}\text { Adherence } \\
\text { year } 1, \\
\text { median } \\
\text { (IQR) }\end{array}$} & MPR & $0.89(0.49-1.00)$ & $0.90(0.54-1.00)$ & $0.90(0.50-1.00)^{\mathrm{i}}$ & $0.88(0.46-1.00)^{\mathrm{d}, \mathrm{e}}$ & $0.90(0.50-1.00)$ & $0.92(0.54-1.00)^{\mathrm{f}}$ & $0.82(0.46-0.98)^{f, g}$ \\
\hline & $\begin{array}{l}\text { PDC without } \\
\text { stockpilingh }\end{array}$ & $0.81(0.46-0.91)$ & $0.82(0.51-0.92)$ & $0.82(0.46-0.92)$ & $0.79(0.46-0.91)^{\mathrm{d}, \mathrm{e}}$ & $0.82(0.47-0.92)$ & $0.82(0.50-0.91)$ & $0.76(0.46-0.90)^{\mathrm{f}, \mathrm{g}}$ \\
\hline & $\begin{array}{l}\text { PDC with } \\
\text { stockpilingh }\end{array}$ & $0.88(0.48-0.98)$ & $0.89(0.54-0.98)$ & $0.88(0.49-0.98)$ & $0.87(0.46-0.98) \mathrm{d}, \mathrm{e}$ & $0.89(0.50-0.98)$ & $0.92(0.54-0.99)^{\mathrm{f}}$ & $0.81(0.46-0.97)^{\mathrm{f}, \mathrm{g}}$ \\
\hline & $\mathrm{mPDC}$ & $0.86(0.47-0.98)$ & $0.87(0.54-0.98)$ & $0.87(0.48-0.98)$ & $0.84(0.46-0.97) \mathrm{d}, \mathrm{e}$ & $0.87(0.49-0.98)$ & $0.89(0.54-0.98)^{f}$ & $0.79(0.46-0.96)^{f, g}$ \\
\hline \multirow{5}{*}{$\begin{array}{l}\text { Adherence } \\
\text { year } 2 \\
\text { median } \\
\text { (IQR) }\end{array}$} & $\begin{array}{l}\text { Number } \\
\text { taking BP }\end{array}$ & $N=35,456$ & $\mathrm{n}=12,769$ & $\mathrm{n}=11,700$ & $\mathrm{n}=10,987$ & $\mathrm{n}=22,918$ & $\mathrm{n}=6,528$ & $\mathrm{n}=6,010$ \\
\hline & MPR & $0.84(0.46-0.97)$ & $0.84(0.46-0.97)$ & $0.85(0.46-0.97)$ & $0.84(0.46-0.97)$ & $0.85(0.46-0.97)$ & $0.87(0.51-0.98)^{f}$ & $0.77(0.38-0.96)^{f, g}$ \\
\hline & $\begin{array}{l}\text { PDC without } \\
\text { stockpilingh }\end{array}$ & $0.76(0.41-0.89)$ & $0.75(0.44-0.89)$ & $0.76(0.41-0.90) \mathrm{j}$ & $0.75(0.39-0.89)$ & $0.76(0.42-0.90)$ & $0.76(0.46-0.89)$ & $0.69(0.33-0.88)^{f, g}$ \\
\hline & $\begin{array}{l}\text { PDC with } \\
\text { stockpilingh }\end{array}$ & $0.86(0.46-0.98)$ & $0.85(0.47-0.98)$ & $0.86(0.46-0.98)$ & $0.86(0.46-0.98)$ & $0.86(0.46-0.98)$ & $0.89(0.53-0.99)^{f}$ & $0.78(0.39-0.97)^{\mathrm{f}, \mathrm{g}}$ \\
\hline & $\mathrm{mPDC}$ & $0.84(0.46-0.97)$ & $0.83(0.46-0.96)$ & $0.84(0.46-0.97)$ & $0.84(0.46-0.97)$ & $0.84(0.46-0.97)$ & $0.86(0.50-0.98)^{\mathrm{f}}$ & $0.76(0.38-0.95)^{f, g}$ \\
\hline \multirow{5}{*}{$\begin{array}{l}\text { Adherence } \\
\text { year } 3 \text {, } \\
\text { median } \\
\text { (IQR) }\end{array}$} & $\begin{array}{l}\text { Number } \\
\text { taking BP }\end{array}$ & $\mathrm{N}=30,233$ & $\mathrm{n}=10,886$ & $\mathrm{n}=10,010$ & $\mathrm{n}=9,337$ & $\mathrm{n}=19,427$ & $\mathrm{n}=5,755$ & $\mathrm{n}=5,051$ \\
\hline & MPR & $0.85(0.51-0.97)$ & $0.84(0.50-0.97)$ & $0.86(0.54-0.97)^{\mathrm{d}}$ & $0.85(0.50-0.97)$ & $0.85(0.51-0.97)$ & $0.89(0.60-0.98)^{f}$ & $0.79(0.46-0.96)^{\mathrm{f}, \mathrm{g}}$ \\
\hline & $\begin{array}{l}\text { PDC without } \\
\text { stockpilingh }\end{array}$ & $0.76(0.46-0.89)$ & $0.75(0.46-0.88)$ & $0.77(0.46-0.89)^{\mathrm{d}}$ & $0.76(0.46-0.89)^{\mathrm{e}}$ & $0.76(0.46-0.89)$ & $0.77(0.48-0.89)$ & $0.72(0.41-0.88)^{f, g}$ \\
\hline & $\begin{array}{l}\text { PDC with } \\
\text { stockpilingh }\end{array}$ & $0.87(0.53-0.98)$ & $0.86(0.52-0.98)$ & $0.88(0.55-0.98)^{\mathrm{d}}$ & $0.87(0.51-0.98)^{\mathrm{k}}$ & $0.87(0.53-0.98)$ & $0.91(0.61,0.99)^{\mathrm{f}}$ & $0.81(0.46-0.97)^{\mathrm{f}, \mathrm{g}}$ \\
\hline & $\mathrm{mPDC}$ & $0.85(0.52-0.97)$ & $0.84(0.50-0.96)$ & $0.85(0.54-0.97) \mathrm{d}$ & $0.85(0.50-0.97)^{1}$ & $0.85(0.51-0.97)$ & $0.88(0.60-0.98)^{f}$ & $0.79(0.46-0.95)^{\mathrm{f}, \mathrm{g}}$ \\
\hline \multicolumn{9}{|c|}{ Nonpersistence $^{b}$} \\
\hline \multicolumn{2}{|c|}{$\begin{array}{l}\text { Persistence }<100 \% \\
\text { (or gap > } 60 \text { days), n (\%) }\end{array}$} & $18,174(42.9)$ & $6,511(43.5)$ & $5,929(42.6)$ & $5,734(42.4)$ & $11,387(41.3)$ & $3,260(43.8)$ & $3,527(48.1)$ \\
\hline \multicolumn{2}{|c|}{$\begin{array}{l}\text { cumulative nonpersistent } \\
\text { intervals, years, median (IQR) }\end{array}$} & $0.65(0.30-1.25)$ & $0.62(0.30-1.19)$ & $0.66(0.31-1.27)^{\mathrm{m}}$ & $0.67(0.31-1.31)^{d}$ & $0.63(0.29-1.24)$ & $0.65(0.32-1.21)$ & $0.71(0.35-1.30)^{\mathrm{f}, \mathrm{n}}$ \\
\hline
\end{tabular}

aWilcoxon rank-sum test was used for the comparisons of persistence, adherence, and nonpersistence.

bPersistence and nonpersistence are expressed in median years (IQR) using the MPDC approach for assigning drug exposure. Initial persistence was measured from the

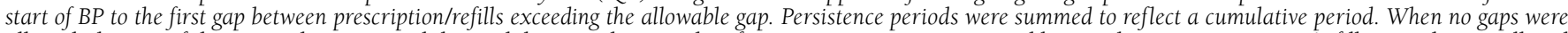

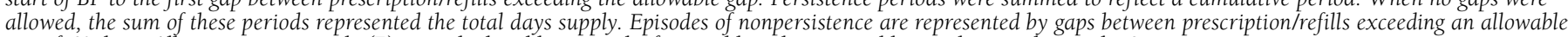
gap of 60 days. All summative periods $(\Sigma)$ are calculated between the first and last day covered by BP therapy during the 3 years.

${ }^{c} P=0.045$ compared with 50-64 years.

$d P<0.001$ compared with $50-64$ years.

${ }^{e} \mathrm{P}<0.001$ compared with $65-74$ years.

$f_{P}<0.001$ compared with whites.

$g P<0.001$ compared with Asians.

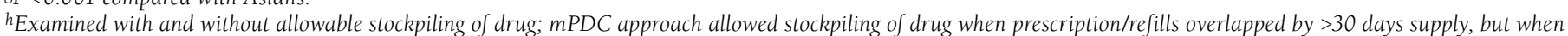
prescription/refills overlapped by $>30$ days supply, the second prescription/refill took precedence.

i $P=0.041$ compared with 50-64 years.

$j P=0.019$ compared with 65-74 years.

${ }^{k} P=0.047$ compared with 65-74 years

${ }^{l} P=0.025$ compared with $65-74$ years

$m P=0.002$ compared with 65-74 years

nP $=0.009$ compared with Asians.

$B P=$ bisphosphonate $I Q R=$ interquartile range; $m P D C=$ (modified) proportion of days covered; $M P R=$ medication possession ratio; $P D C=$ proportion of days covered . 


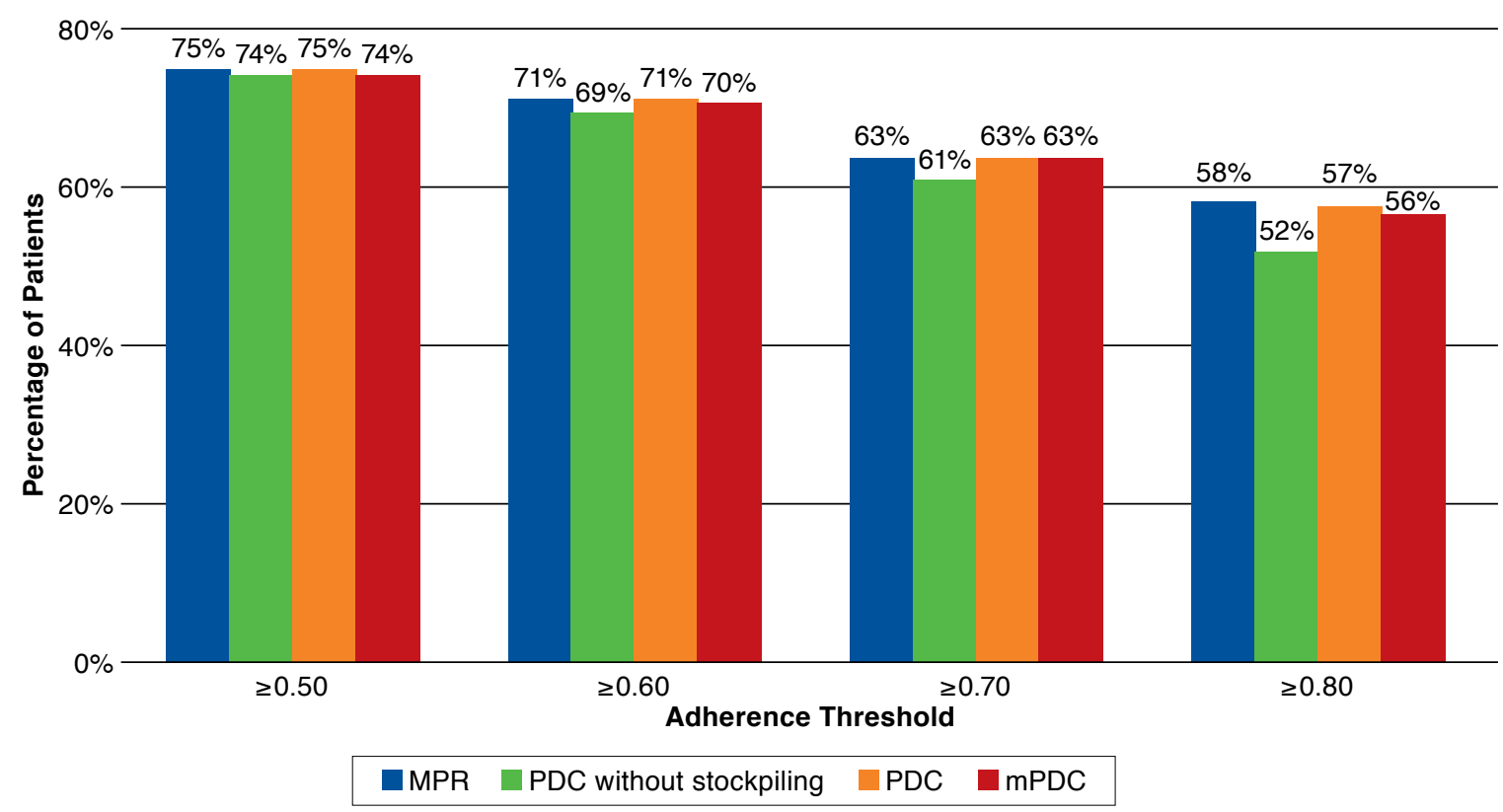

Note: Adherence was classified using 4 measures: MPR, PDC with stockpiling, PDC without stockpiling, and $m$ PDC to allow stockpiling $\leq 30$ days. $B P=$ bisphosphonate $\quad m P D C=$ (modified) proportion of days covered; $M P R=$ medication possession ratio; $P D C=$ proportion of days covered .

Similar to the observed trends in BP discontinuation, older age was associated with slightly longer cumulative periods of nonpersistence (Table 1). Women of other race/ethnicity had a longer cumulative period of nonpersistence compared with women of Asian or white race (Table 2).

Optimal adherence in year 1 ( $\geq 75 \%$ using mPDC) was strongly associated with adherence in subsequent years. Women with an adherence of $\geq 75 \%$ in year 1 had a 12 -fold increased odds of achieving optimal adherence in year 2 (ageand race-adjusted $\mathrm{OR}=11.8,95 \% \mathrm{CI}=11.2-12.5)$ and a 6 -fold increased odds of achieving optimal adherence in year 3 (ageand race-adjusted $\mathrm{OR}=5.7,95 \% \mathrm{CI}=5.4-6.0$ ) when compared with women with adherence $<75 \%$ in year 1 . These results were similar when adherence was assessed using MPR (data not shown).

\section{Discussion}

Within a large and diverse cohort of women initiating oral BP therapy, we observed that more than 1 in 4 women did not continue any BP treatment during the second and third year of follow-up. However, among those with evidence of treatment after the first year, subsequent discontinuation rates were lower and varied somewhat by age and race. Up to $60 \%$ of the women achieved an adherence $\geq 75 \%$ in the first year, which was highly predictive of subsequent adherence and continuation of BP use.
These results may have important population management implications, where targeted outreach may especially benefit those who discontinued BP or had low adherence during the first year. We also found that various methods used to define adherence yield similar results to MPR, thus justifying this simpler calculation when assessing early usage patterns.

In comparison, several previous studies have reported lower adherence with oral BP therapy, based on the proportion of nonadherent individuals defined by MPR threshold (e.g., $0.80 \%$ or $80 \%)^{6,9,17,18}$ and overall lower MPR. ${ }^{2,19-21}$ In a meta-analysis of 15 studies from 2004-2009, Imaz et al. (2010) estimated a pooled MPR of $67 \%,{ }^{5}$ whereas in another systematic review, Kothawala et al. (2007) estimated a pooled MPR of $68 \% .{ }^{6}$ In our study, we observed a higher median adherence based on either MPR (median 89\%) or mPDC (median $86 \%$ ) within the first year, although a large percentage (39.6\%) within the cohort did not achieve adherence $\geq 75 \%$. The higher adherence observed in our study may reflect the near exclusive use of weekly BP dosing regimens (shown previously to be associated with greater adherence when compared with daily regimens), ${ }^{22,23}$ high prevalence of dispensing a 3-month supply, ${ }^{24}$ a convenient refill system, and regional efforts to improve fracture prevention education among seniors. In addition, our requirement of 2 filled prescriptions before 
ascertaining adherence among BP users may also increase population adherence estimates (12.5\% with only 1 filled prescription were excluded from adherence analyses, and women with primary nonadherence were not ascertained in this study). ${ }^{25}$ Other studies have reported high rates of primary nonadherence (i.e., not picking up the first prescription) 2-12 months following the initial BP prescription. ${ }^{26-28}$ In our study, we found that nearly half of the women who continued treatment into year 3 achieved an annual MPR and/or mPDC threshold of 75\% over all 3 years of the study. Siris et al. (2006) looked at the relationship between adherence rates and fracture risk, observing a graded relationship where the reduction in fracture risk was most evident at MPR $\geq 75 \%$, suggesting that this threshold is a clinically meaningful one. ${ }^{9}$

In this study, we did not use the gap between prescription and refills to define discontinuation, given previous evidence that discontinuation rates vary substantially depending on the size of the allowable gap. ${ }^{7}$ Instead, we determined persistence and nonpersistence over the 3 years of observation and characterized adherence based on PDC (from the prescription days supply) for each year of follow-up. Using this approach, the majority of women demonstrated treatment persistence for at least 2 of the 3 years of observation, but up to $43 \%$ of the women demonstrated at least 1 nonpersistent interval (gap $>60$ days). Data from Ontario, Canada, found that $61 \%$ of new users experienced at least 1 treatment gap $>60$ days when examining persistence over a 5 -year period, ${ }^{29}$ underscoring that some nonpersistence is common with BP therapy.

We also found that across varying methods used for defining treatment adherence and persistence, Asian women had somewhat greater adherence and longer treatment persistence compared with white women, although these differences were small and their clinical significance unclear. However, these findings are among the first to characterize early BP exposure in a large and ethnically diverse population of older women receiving BP therapy, including exposure patterns among Asian women, where slightly greater adherence and persistence contribute to overall greater drug exposure. Previously, we examined cumulative BP duration within this cohort during a median follow-up of 7.7 years, ${ }^{13}$ but these current analyses focused on patterns of adherence, persistence, nonpersistence, and discontinuation identified during the first 3 years of observation.

Others have examined race-related differences among patients of other race or ethnicities, including white and black adults and white, black, and Hispanic adults receiving Medicare, ${ }^{30,31}$ but few studies have examined osteoporosis drug adherence patterns among populations that include a large percentage of Asians. In a study of primary nonadherence to BP in postmenopausal Southern California women, Reynolds et al. (2013) observed that primary nonadherence was similar among postmenopausal Asian and white women but did not examine differences in adherence and persistence once women initiated BP therapy. ${ }^{26}$
The strengths of this study include the comprehensive tracking of pharmacy exposure within a large population of nearly 50,000 women, where high membership retention rates among health plan seniors allowed detailed characterization of adherence, persistence, and discontinuation rates during follow-up. Furthermore, the ethnic diversity of the cohort enabled examination of race-specific differences in ways that might not be feasible for other institutions.

\section{Limitations}

This study, however, also has some limitations to consider. First, the electronic prescription records may not reflect whether the patient is actually taking the medication; for this reason, our adherence measures required a minimum of 2 prescriptions per person. Even so, systematic overestimation of BP exposure cannot be excluded. Second, we allowed some stockpiling of drugs except for instances of substantial prescription overlap, which may have led to occasional misclassification of exposure, including under- or overestimation. Third, we did not examine the reason for initiating oral BP therapy and bone health outcomes that might have affected treatment patterns. Fourth, our health plan implemented strategies for greater osteoporosis awareness and fracture prevention during the past decade, resulting in findings less generalizable to populations without similar clinical care management programs. However, our study cohort arose from a well-characterized source population found to be generally reflective of the demographics of the geographic area served in northern California. ${ }^{32}$ Finally, this study was conducted within an integrated health care delivery system where there may be fewer barriers to care, which may limit the generalizability of our findings to other practice settings.

\section{Conclusions}

We examined BP adherence, persistence, nonpersistence, and treatment discontinuation using established methods that were easily adapted for use in a large pharmacy database. These various methods yielded similar results when examined in women followed for 3 years. While discontinuation rates were highest during the first year, adherence was relatively stable among those continuing treatment beyond the first year. Adherence and persistence varied somewhat by race group and age, with adherence and persistence somewhat higher in Asian women, contributing to differences in cumulative BP exposure. Finally, adherence during the first year was strongly predictive of adherence in subsequent years. These findings suggest that there may be certain subgroups of women for whom outreach and closer monitoring of BP use may be warranted to better achieve maximum fracture reduction benefit in vulnerable patients with low adherence. Further studies are needed to understand factors contributing to suboptimal adherence with continued therapy to inform efforts at improving usage of these and other osteoporosis medications that reduce fracture risk. 


\section{Authors}

RITA L. HUI, PharmD, MS, Pharmacy Outcomes Research Group, Kaiser Permanente California, Oakland. MALINI CHANDRA, MS, MBA; JOAN C. LO, MD; and BRUCE ETTINGER, MD, Division of Research, Kaiser Permanente Northern California, Oakland. ANNETTE L. ADAMS, PhD, MPH, and DAVID K. YI, MPH, Department of Research E Evaluation, Kaiser Permanente Southern California, Pasadena. FANG NIU, MS, Pharmacy Outcomes Research Group, Kaiser Permanente California, Downey.

AUTHOR CORRESPONDENCE: Rita L Hui, PharmD, MS, Pharmacy Outcomes Research Group, Kaiser Permanente California, 1800 Harrison St., \#1301, Oakland, CA 94612. Tel.: 510.625.3948; E-mail: Rita.L.Hui@kp.org.

\section{DISCLOSURES}

This study was supported by grants from the Kaiser Permanente Northern California Community Benefit Program and the National Institutes of Health, 1R01AG047230-01Al. The opinions expressed in this publication are solely the responsibility of the authors and do not represent the official views of Kaiser Permanente or the National Institutes of Health. Hui, Yi, and Chandra have received past research funding from Amgen not related to the current study. Adams has received research funding from Amgen, Merck, and Otsuka not related to the current study. Niu has received research funding from Bristol-Myers Squibb not related to the current study. Ettinger has received past legal fees in litigation involving Fosamax. Lo has received past research funding from Amgen and current research funding from Sanofi not related to the current study.

The data from this study were presented at the Academy of Managed Care Pharmacy Annual Meeting; April 19-22, 2016; San Francisco, California.

Study concept and design were contributed primarily by Hui and Lo, along with Adams, Niu, Yi, and Ettinger. Hui took the lead in data collection, along with Chandra, and data interpretation was performed by Niu, Yi, and Lo, along with the other authors. The manuscript was written by Hui, Adams, and Lo, along with Niu, Yi, and Ettinger, and revised by Ettinger, Hui, Lo, and Niu, along with the other authors.

\section{REFERENCES}

1. Andrade SE, Kahler KH, Frech F, Chan KA. Methods for evaluation of medication adherence and persistence using automated databases. Pharmacoepidemiol Drug Saf. 2006;15(8):565-74; discussion 75-77.

2. Cramer JA, Roy A, Burrell A, et al. Medication compliance and persistence: terminology and definitions. Value Health. 2008;11(1):44-47.

3. Parker MM, Moffet HH, Adams A, Karter AJ. An algorithm to identify medication nonpersistence using electronic pharmacy databases. J Am Med Inform Assoc. 2015;22(5):957-61.

4. Raebel MA, Schmittdiel J, Karter AJ, Konieczny JL, Steiner JF. Standardizing terminology and definitions of medication adherence and persistence in research employing electronic databases. Med Care. 2013;51(8 Suppl 3):S11-21.

5. Imaz I, Zegarra P, Gonzalez-Enriquez J, Rubio B, Alcazar R, Amate JM. Poor bisphosphonate adherence for treatment of osteoporosis increases fracture risk: systematic review and meta-analysis. Osteoporos Int. 2010;21(11):1943-51.

6. Kothawala P, Badamgarav E, Ryu S, Miller RM, Halbert RJ. Systematic review and meta-analysis of real-world adherence to drug therapy for osteoporosis. Mayo Clin Proc. 2007;82(12):1493-501.
7. Lo JC, Pressman AR, Omar MA, Ettinger B. Persistence with weekly alendronate therapy among postmenopausal women. Osteoporos Int. 2006;17(6):922-28.

8. Karter AJ, Parker MM, Moffet HH, Ahmed AT, Schmittdiel JA, Selby JV. New prescription medication gaps: a comprehensive measure of adherence to new prescriptions. Health Serv Res. 2009;44(5 Pt 1):1640-61.

9. Siris ES, Harris ST, Rosen CJ, et al. Adherence to bisphosphonate therapy and fracture rates in osteoporotic women: relationship to vertebral and nonvertebral fractures from 2 U.S. claims databases. Mayo Clin Proc. 2006;81(8):1013-22

10. Lin JH. Bisphosphonates: a review of their pharmacokinetic properties. Bone. 1996;18(2):75-85.

11. Wysowski DK, Greene P. Trends in osteoporosis treatment with oral and intravenous bisphosphonates in the United States, 2002-2012. Bone. 2013;57(2):423-28.

12. Hoeffel EM, Rastogi S, Kim MO, Shahid H. The Asian population: 2010. 2010 Census Briefs. U.S. Census Bureau. March 2012. Available at: https:// www.census.gov/prod/cen2010/briefs/c2010br-11.pdf. Accessed February 15, 2017.

13. Lo JC, Hui RL, Grimsrud CD, et al. The association of race/ethnicity and risk of atypical femur fracture among older women receiving oral bisphosphonate therapy. Bone. 2016;85:142-47.

14. Lo JC, Zheng P, Grimsrud CD, et al. Racial/ethnic differences in hip and diaphyseal femur fractures. Osteoporos Int. 2014;25(9):2313-18.

15. Hess LM, Raebel MA, Conner DA, Malone DC. Measurement of adherence in pharmacy administrative databases: a proposal for standard definitions and preferred measures. Ann Pharmacother. 2006;40(7-8):1280-88.

16. Nau D. Proportion of days covered (PDC) as a preferred method of measuring medication adherence. Pharmacy Quality Alliance. 2015. Available at: http://www.pqaalliance.org/images/uploads/files/PQA\%20PDC\%20vs\%20 \%20MPR.pdf. Accessed February 15, 2017.

17. Carr AJ, Thompson PW, Cooper C. Factors associated with adherence and persistence to bisphosphonate therapy in osteoporosis: a cross-sectional survey. Osteoporos Int. 2006;17(11):1638-44.

18. Modi A, Siris ES, Tang J, Sen S. Cost and consequences of noncompliance with osteoporosis treatment among women initiating therapy. Curr Med Res Opin. 2015;31(4):757-65.

19. Martin KE, Yu J, Campbell HE, Abarca J, White TJ. Analysis of the comparative effectiveness of 3 oral bisphosphonates in a large managed care organization: adherence, fracture rates, and all-cause cost. J Manag Care Pharm. 2011;17(8):596-609. Available at: http://www.jmcp.org/doi/10.18553/ jmcp.2011.17.8.596.

20. Wade SW, Curtis JR, Yu J, et al. Medication adherence and fracture risk among patients on bisphosphonate therapy in a large United States health plan. Bone. 2012;50(4):870-75.

21. Weycker D, Lamerato L, Schooley S, et al. Adherence with bisphosphonate therapy and change in bone mineral density among women with osteoporosis or osteopenia in clinical practice. Osteoporos Int. 2013;24(4):1483-89.

22. Brankin E, Walker M, Lynch N, Aspray T, Lis Y, Cowell W. The impact of dosing frequency on compliance and persistence with bisphosphonates among postmenopausal women in the UK: evidence from three databases. Curr Med Res Opin. 2006;22(7):1249-56.

23. Ettinger MP, Gallagher R, MacCosbe PE. Medication persistence with weekly versus daily doses of orally administered bisphosphonates. Endocr Pract. 2006;12(5):522-28.

24. Taitel M, Fensterheim L, Kirkham H, Sekula R, Duncan I. Medication days' supply, adherence, wastage, and cost among chronic patients in Medicaid. Medicare Medicaid Res Rev. 2012;2(3):mmrr.002.03.a04. Available at: https://www.ncbi.nlm.nih.gov/pmc/articles/PMC4006393/. Accessed February 15, 2017. 
25. Raebel MA, Carroll NM, Ellis JL, Schroeder EB, Bayliss EA. Importance of including early nonadherence in estimations of medication adherence. Ann Pharmacother. 2011;45(9):1053-60.

26. Reynolds K, Muntner P, Cheetham TC, et al. Primary non-adherence to bisphosphonates in an integrated healthcare setting. Osteoporos Int. 2013;24(9):2509-17.

27. Cook PF, Emiliozzi S, McCabe MM. Telephone counseling to improve osteoporosis treatment adherence: an effectiveness study in community practice settings. Am J Med Qual. 2007;22(6):445-56.

28. Waalen J, Bruning AL, Peters MJ, Blau EM. A telephone-based intervention for increasing the use of osteoporosis medication: a randomized controlled trial. Am J Manag Care. 2009;15(8):e60-70.

29. Burden AM, Paterson JM, Solomon DH, Mamdani M, Juurlink DN, Cadarette SM. Bisphosphonate prescribing, persistence and cumulative exposure in Ontario, Canada. Osteoporos Int. 2012;23(3):1075-82.
30. Gerber BS, Cho YI, Arozullah AM, Lee SY. Racial differences in medication adherence: a cross-sectional study of Medicare enrollees. Am J Geriatr Pharmacother. 2010;8(2):136-45.

31. Gellad WF, Haas JS, Safran DG. Race/ethnicity and nonadherence to prescription medications among seniors: results of a national study. J Gen Intern Med. 2007;22(11):1572-78.

32. Gordon NP. Similarity of the Kaiser Permanente senior member population in Northern California to the non-Kaiser Permanente covered and general population of seniors in Northern California: statistics from the 2009

California Health Interview Survey. Kaiser Permanente Northern California Division of Research. January 6, 2012. Available at: http://www.dor.kaiser. org/external/chis_kpnc_seniors_2009/. Accessed February 15, 2017. 


\section{APPENDIX Sample Attrition}

Without 1 year membership before $(n=996)$

Without 3 years membership after $(n=8,014)$

Intravenous BP users $(n=1,268)$

All women aged $\geq 50$ years who first used oral BPs between January 2002 and December 2007

$$
\mathrm{N}=57,104
$$

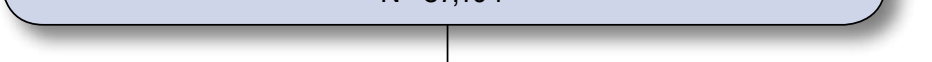

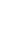

\section{Final cohort}

$n=48,390$

BP= bisphosphonate 